\title{
Derivational Valency and Potential of Combining Forms in Present-Day English Word-Building
}

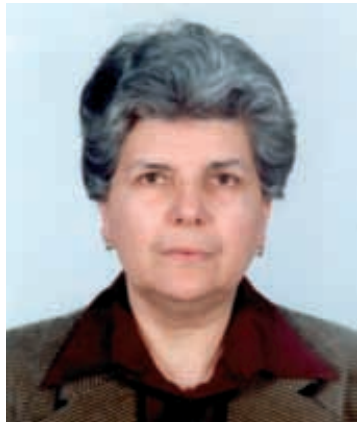

Aida Alanakyan

$\mathrm{T}$ The present article aims at outlining the area of new coinages formed by means of so-called combining forms with the view of disclosing the part that they play in the system of modern English word-formation. It is noteworthy that notwithstanding the growing interest in linguistic units generally known as "combining forms" and the rapid proliferation of words coined with the help of such elements in the last three decades, linguists hold rather divergent views upon the status and nature of the units in question. Thus, some scholars treat them as semi-affixes, i.e. derivational morphemes similar to prefixes and suffixes (Arnold I.V., 1973; Ginzburg R.S. et al., 1979; Marchand H., 1969), whereas others argue that these units are" bound morphemes of a special kind called “combining forms” (Bauer L., 1983, Nurnberg M. and Rosenblaum M., 1968).

That is the reason why the present paper does not focus on the theoretical aspects of" this complex problem, but attempts at a lexicographic description of combining forms" by relying on dictionaries of neologisms in which they are unambiguously referred to as" combining forms (further - CF's).

As a matter of fact, our research is fully based on the data provided by the two" editions of the Oxford Dictionary of New Words, 1991 and 1997 respectively, in addition" to some data extracted from the New English-Russian Dictionary compiled by" Yu.Apresyan. The total number of CF's under study amounts to 29 entries: -Aid, -babble, bio-, -core, cryo-, cyber-, dino-, docu-, e-, eco-, electro-, Euro-, -free, -friendly, -gate, info-, immuno-, -line, nano-, nega-, -nomics, of-, -on-demand, -rage, -size, tele-, über-, -ware, -watch.

Obviously, the selected CF's are far from being homogeneous, but make a rather" varied group differing in their position within a word, semantic loading, origin, lexicogrammatical valency, derivational potency and some other respects.

To begin with, according to their position with regard to the root morpheme, the CF's" can be conventionally divided into those which are characterized by a fixed position in 
the word and those which are comparatively free in their distribution. Among the former group we can single out $/ \mathrm{CF}$ 's occurring in initial position (ICF's) such as bio-, cryo-, wher-, dino-, eco-, electro-, Emo-, info-, immuno-, nano-, nega-, of-, tele- (14 in all), whereas the rest of the whole list except doc/doct- occur in final position (FCF's), including such units as -Aid. -free, firiendly, etc. As for C'F's which have no prescriptive position in words, they are represented in our material by one morpheme alone, namely, doc/doct- (Cf. dramadoc, docudrama, docutainment).

Commenting on the valency of the selected CF's, we are to state that most of them occur in combination with noun bases (e.g. school-Aid, cryo-bank, bioenergy, infosphere, meat-fiee, Elrojargon), though there are some which may appear in combination with genume adjective stems or CF's of adjectival character (e.g. ecocentric. ecopsychology. (ryogenetic, Euroconvertible. Euro-sceptic, immumodefficient). As to the inorphological structure of the stems to which the CF's are added, here belong simple, derived, as well as compound stems, though the latter case is rather rare. Cf. teletext, ecotype, earo-issue, carefice, biosphere (with simple stens); biodegradable, biopreparation (with derived stems); biofeedback (with compound stems).

it must be added that in all the words mentioned above, the CF's perform an attributive function as the lexico-semantic centre lies in the second component, whereas the first element is similar to a modifier: $\mathrm{Cf}$ ::

infosphere - area of activity concerned with processing of information,

Ewrobin - large wheeled rubbish bin produced according to European standards,

nega-demand - reduced demand of resources,

clectro-jazz-jazz music perfomed by heavy use of electronic instruments.

In other cases, however, the relations between the CF and the other constituent of the word may be estimated as those of semantic coordination, as illustrated by the following words:

Biomathematics - science of application of mathematics to biology;

cryosurgery - surgery which uses intense cold to remove or destroy tissues just as effectively as heal.

These words can be referred to as coordinative composites of the additive type. Functionally, they are terminological coinages and like other terms tend to be monosemantic.

Before turning to the detailed analysis of the CF's in our selection. it is worth discussing some of the characteristic features proper to them. One of the peculiarities of the CF's under study is that, apart from words in which a CF is added to a derivational bise, quite a number of new coinages are made by juxtaposing two CF's, which testifies to the increasing derivational valency of these units:

e.g. Eurohabble - the jargon of European Community documents and regulations eco-friendly - causing little harm to the environment, ecologically sound.

Another evidence confirming this statement is that CF's may be fixed to clipped parts of words (or splinters) and create blends as a result. Although most of the recent coinages of this kind are ephemeral, they are rather frequent in the language of advertising, journalism and business. Below are some examples: 
ecotopian $=e c o-+$ utopia - an ecologically ideal society

docutainment $=$ doct - + enterainment - designed both to inform and to entertain form of a short $=$ info- + commercial - a television or radio commercial presented in the

Apart from the above mentioned fact

"specific gravity" of CF's in moded factors responsible for the further growth of the discussing here. We mean thodern English word-building, there is another point worth Particularly, the combining fome of them can serve as bases for coining new units. the late eighties gave rise form - w'atch usually forming nouns due to its popularity in CF's -watcher and - verbs (as in to whale-watch), and still further the that CF's take an acesult of back derivation. It follows derivation the bord-creation, namely blending and backAs for the latter gaining an increasing popularity nowadays.

As for the etymological classification of the selected CF's, it must be stated that a considerable number of CF's are of foreign origin, particularly of Greek and Latin descent, which holds true mainly for CF's that occur in pre-position in neo-classical compounds and are marked by a great combining power producing so-called "open" series of words.

It must be noted in passing that apart from Greek and Latin CF's, among foreign units there is one of German origin, namely the combining form über-which came down from the first element of the German word "Übermensch" (superman) and hence the new coinages "überboomer", über-TVshow, über-Babes (sporty models).

Except for über-which is represented by a limited number of coinages, the initial CF's of Greek origin should be estimated as the most popular and productive, judging by the number of recent formations. If arranged in descending urder, all the selected
initial combining forms (irrespective of the origin) may look like this:

Euro- (35 units), eco- (28), cyber- (21), bio- (18), tele-(14), of-(13), info-(11), nano(11), cryo- (9), immuno- (7), electro- (6), nega- (4), doct- (3), über- (3).

An analogous procedure applied with regard to final combining forms has yielded the following figures: free (15), -ware (15), -fiendly (10), -on-demand (9), -line (8), watch (6), -Aid (5), -rage (5), -size (5), -babble (4), -nomics (4).

Unlike the previous group of initial CF's characterized by the predominance of Greek and Latin elements, this list is less homogeneous, as far as the origin of the CF's is concerned, since it is represented either by free-standing forms or stems (-free, friendly, -gate, -watch, etc.) of native origin or by splinters (like-nomics) resultant from
the clipping of current English words.

Our study of the data shows that the units Euro-, -eco-, bio-among the CF's of the first group and -fiee, -ware, friendly in the second list respectively, have the highest frequency value of occurrence among recent coinages. And therefore, they require a more detailed discussion. Indeed, it is necessary to take a closer look at the factors
conducing to their rise and derivational potential.

In this respect, the unit Euro- stands somewhat apart from the rest of initial CF's for several reasons.

Firstiy, Euro- is not only a combining form widely used in words relating to Europe. the European Community, or European money market, but it is also a free-standing 
IHentesyllabic word used to designate the European currency unit.

Secondly, Euro- can be combined with another CF to make a new word, as is the case ivith the words Eurobabble (Euro- + -babble) and Eurocrat (Euro- +-crat), the former kenoting jargon-ridden forms of the language which sound nonsensical to those who are $n 01$ aware of them. Accordingly, the word Eurocrat stands for a European bureaucrat.

Besides, Euro-displays a strong tendency to combine with abbreviations and acronyms, as is the case with Euro-MP = Member of European Parliament.

In general, according to all lexicographic estimates, Eum- has enjoyed two periods of great vogue in English: first, during the sixties when British membership was under discussion and second. when EC institutions and standards began to impinge on the British way of life and when the question of European integration arose.

The Euro- words of the first period include Europlanet, Euroissue, Eurosummit and the like.

The second period has produced a greater variety of words which relate to almost every sphere of social, political, economic and cultural life. The rapid growth of the market functioning in Eurocurrencies and Eurobonds resulted in a wide usage of Euroin financial terms in the late eighties and early nineties. For instance, the adjective Euroconvertible came to be applied to Eurobonds which can be converted into another type of security. By the late seventies it had also become a fashionable form applied to all consumer goods, etc. produced up to EC standards, for instance: Eurobottle. Europack, Euo-pass, Eurocode.

On the other hand, the inability of EC countries to cope with the commercial challenges of new technology was labelied Euroxcleresis. In the context of the opposition to the deployment of missiles and heated discussions in the US over subsidies given to European firms setting up business of marketing products there, the words Euromissiles and Eurosubsidies appeared. In addition, the adjective Euro-sceptic came into being to describe politicians who considered 100 minutely all pros and cons of European integration in the late eighties.

Quite independent of the EC, an important political formation of the second half of the seventies, was the rise of Eurocommunism - a brand of comınunism which emphasized acceptance of democratic institutions and sought to influence European politics from within; in the mid-eighties the Eurocommumists and Eurosocialists sought to resolve their differences and reform under the more general heading of Euroleft.

As for the CF eco-, it has penetrated almost into all the spheres of social life. but is especially common in compounds and blends relating to ecology, the environment or "green" issues.

There are particularly two specific features as regards this combining form, namely:

1. Like Euro-, it tends to be affixed to other CF's to create new words. For example,

ecobabble $=e c(0-+$ - babble

ecofriendly $=e c o-+$-friendly

2. Besides, it is capable of forming blends. For example, ecotastrophe $=e c 0-+$-catastrophe

Ecotopia $=$ ecological + Utopia 
ecotage $=$ ecological sabotage

The combining form eco-began to enjoy popularity particularly in the eighties, being widely applied in scientific teminology: e.g. ecoctimate, ecosphere, ecospecies, ecosystem, ecotype etc.

The most long-lived words in this set are: eco-dware, eco-centric, ecoconciousness, ecocrisis, ecopolitics and eco-terrorist/eco-guerilla.

Totally, the number of words crcated by the combining form eco-amounts to 28 , which is indicative of the high rate of combinability and thus, productivity of this unit,

Next comes the combining form bio- of Greek origin used in compounds relating to "life". Actually, it is defined as part of the words "biology" and "biological", widely used as the first element of compounds relating to "biology" and "biotechnology". Due to the advance in technology and increasing interest in environmental issues, this combining form is widely used nowadays.

The development of plastics and other synthetic products which are biodegrackble, that is, those that would decompose spontaneously and thus not become an envirommental hazard, has led to the coining of the verb biodegrade through back-derivation.

Another point of interest concerning this $\mathrm{CF}$ is that it is also capable of linking up with compound stems, as is the case with the word feedback, from which we have biofeedback - the term for one of the techniques applied in autogenetic training.

Let us now turn to the other group of final CF's anong which the most productive, according to our counts, are -free and -friendly.

Concerning the productive combining form -fiee, it must be stated that originally it meant "exempt from tax or charge", but at present it has developed four new meanings. that is to say, is chlaracterized by a complex semantic structure. Actually, now it occurs in words as the second element and means "not containing or involving usually undesirable ingredients, factors, etc., named in the word by the preceding stem or form". Cf.:

1. -free - not hampered by the trouble named in the first element (e.g. carefiee, troublefree. etc.);

2. -free - used in combination with words meaning special diets (e.g. alcohol-free, sugar-fiee, dairy-free, cholesterol-free, etc.):

3. -free - used in combination with words to do with pollutants and additives (e.g. additive-free, alar-free, lead-free, etc.);

4. -fire - used in combination with words which indicate the undesirable process of an illness or infection (e.g. salmonella-free, enzyme-free, etc.).

As a matter of fact, -free may occur in a latge number of words belonging to various fields of scientific knowledge and human activities, the number of such words amounting to 19.

A similar situation is observed with regard to the combining form-friendly. Actually, these two CF's are alike in many respects, namely, as to their position in the word, their meaning and derivational valency.

To start with, the combining form - friendly' means: either "adapted, designed or made suitable for the person or thing named in the first word," or "safe for, not harmful to what is named before the hyphen". The origin of this CF may be sought in the 
Wrimely successful late-seventies coinage user-friendly, a computing metaphor which wis extended to users of other types of products as well. This was done either by mere weusion of the meaning of the word user-friendly, or by substituting the first component, for instance, reader-friendly, listener-friendly, etc. In the early eighties this ('I' gave rise to a new series of words with a new meaning: e.g. emironment-friendly, thit is, causing little harm to the enviromment. Further, this produced a chain of analogical formations, namely, ozome-friendly. Earth-friendly: planet-friendly: In another firmation of the same type like greenhouse-firiendly, the basic meaning "not harmful to" has been extended to "not contributing to the harmful effect of".

One of the peculiarities of this combining form is its ability to join up with another $C F$ to create a new word. Though this is not of frequent occurrence, such formations show a growing tendency, which may be illustrated by the word ecofiiendly $=$ eco- + -friendly (not harmful for the environment) where both constituent parts are combining forms.

Thus, at least three different meanings can be ascribed to the combining form firiendly:

1. adapted, designed, or made suitable for.

2. safe for, not harmful to.

3. not contributing to the harnful effects of.

Unlike the previously discussed CF's characterized by a wide application in different spheres of social life, the next two CF's, namely, -ware and-on-demand, belong to the specialized field of science and technology. Particularly, this holds true for the CF -ware, which in the main reters to a certain type of software. It is used to form words the first element of which specifies a kind of software in question. Below are some of the coinages with -ware with their dictionary definitions (out of the 15 items available):

freeware - software distributed free to users, without support from the developer

groupucare - a related set of software, software belonging to a group of related packages or designed for using by a workgroup

vapourware - software that as yet only exists in the plans of the developers

crippleware - software which disables programs which require special registration in order to be used

hannerware - software, the principal purpose of which is to advertise another commercial or product.

Of special interest is the multicomponent combining form -on-demand. which differs from the ither CF's in our selection. It is used to form a variety of compounds referring to telecommunication services which are made available when the recipient requests them.

The earliest and the commonest of these terms is video-on-demand, referring to a cable service providing video programmes to be transmitted from a network centre and to be viewed at home, and which the subscribers can freeze or spool forward, as if they were being replayed from their own video recorders.

Later, by analogy with video-on-demand other terms came into existence: nearvideo-on-demand to denote a service in which programmes are repeatedly transmitted on a number of channels within a short period of time and full-video-on-demand - a 
form of an interactive systen. Because most demand is for films, the system is also called film-on-demand. The whole list of coinages with this multicomponent CF amounts to nine items.

In summing up the results of our analysis carried out on the basis of several dictionaries of new words, the following observations can be slated;

1. The selected combining forms make a rather diverse group as regards their morphological, distributional, functional, semantic and derivational characteristics. Thus, from the point of view of their distribution, CF's may occur as the first immediate constiluent of the structural pattern. In this case they tend to combine with a suffix or with another combining form, as well as with a stem consisting of a combining form and a suffix, or of two combining forms. In the latter case the units under study form the semantic centre of the coined word.

2. When used as the second immediate constituent, a combining form may occur both with a suffix and without it. In the former case, we deal with complex and solid derivational units the meaning of which differs from that of the simple combining forms comprising them, and functioning as independent units (without any affixes added to them).

3. Some combining forms occur as equivalents of semantically independent words and represent the clipped forms of these words, which, however, are distinguished from clippings proper since the latter function in speech by themselves and may serve as a derivational base for coining new words.

4. Morphemically, combining forms fall under two large groups, namely, simplexes, which are minimal two-facet language units recurrent in different linguistic environments with stereotyped meanings of their own. Such combining forms make the largest group in our selection (cf. bio-, crio-, info-, etc.). Respectively, the second group of combining forms includes complexes, which comprise two or more morphemes, of which one is a bound root morphene combined with an affix, or a simple combining form plus an affix (e.g. biofeedback). As a matter of fact, our analysis is for the most part restricted to simple forms.

5. The analysis of all the selected forms with regard to their distributional and semantic characteristics has yielded the following results: the combining forms in question can be classified into two groups as to their correlation with independent words or root morphemes:

a) To the first group belong combining forms, which phonetically, structurally and semantically coincide with the clipped form of the word (e.g. info-, $-d o c$, doc $(u)$, electro-, etc.).

b) Accordingly, the second group comprises combining forms, which are not associated with any independently functioning words either in their meaning or in form (e.g. fele-, bio-, crio-, etc.).

6. As for their part-of-speech meaning, most combining forms under study are of substantival or adjectival character (e.g. bio-. cryo-, tele-, -gate, -Aid, -babble, -line, -size, -friendly: etc.).

7. If viowed functionally, most of the combining forms we have studied belong to the 
Itrminological layer of the vocabulary and thus, can be found in different fields of scientific knowledge and human activities, including politics, higher technologies, medicine, etc. Yet, it is worth mentioning that combining forms emerging in one field of semantic and functional field may be introduced into another as a result of close ties between different spheres of human activities or integration of different sciences (e.g. Euro-starting was initially a political term, later it came into common use: eurobottle, euro-pack, etc.).

$x$. As for the derivational potential of the selected combining forms, it must be stated that combining forms are marked by different degrees of productivity, for some of them are represented by a limited number of coinages ( $\mathrm{Cf},-d o c(3)$, immuno- (4), Aid (5)), whereas the number of words coined by means of others amounts to 35 .

1). With regard to derivational combinability, most of the units in our selection are characterized by rather a wide range of valency. They may occur in combination with free morphemes (e.g. Eurobank. infosphere. teletext. etc.) as well as with other combining form(s) (e.g. Eurofitiendly, infotech).

10. Finally, in terms of semantic structure, both monosemantic and polysemantic units are available, the former being predominant.Although most combining forms are characterized by one meaning alone, some, such as -free and -friendly have three or four meanings in their semantic structure.

It is of interest to note that the above-mentioned two units appear to be similar in their meaning to some extent, particularly when denoting "not harmful to". In other words, they may be treated as synonymous.

In addition, some combining forms may display homonymy with other derivational clements, namely, affixes, as is the case with the combining form e-, which formally coincides with the prefixes $e_{-}$and $e_{2-}$. The point is that $e_{-}$as a prefix means "lacking in" (e.g. ecaudate, edentate), while the prefix e:- is the clipped form of the prefix ex- with the meaning "out" (e.g. educe, eject).

As for the combining form $e$ - itself, it can be traced back to two source words: slectronic, on the one hand, and Enropean, on the other. This comes to say that here we deal with two homonymous combining forms, which are semantically diverse. Below are two sets of words comprising different combining forms. $\mathrm{Cf}$.:

$e$-mail (messages distributed by electronic means)

$e-m o n e y$ (term used in electronic financial transactions)

e-number (a code number indicating the correspondence of the food additives to EC standards).

Thus, as can be inferred from the foregoing analysis, the nomenclature of the current CF's steadily increases as a result of an influx of new combining forms, on the one hand, and, on the other hand, as a result of the semantic extension of CF's of long standing.

In addition, it must be stated that the former tendency evolves at the expense of new units which appear to be structurally and semantically so diverse that they defy any clear-cut structural patterning ( $\mathrm{C} f, e$ - and -on-demand). Apart from this, not all the coinages are institutionalized or lexicalized, as most of the new formations are more or less ephemeral by nature. The inclusion of such elements leads to the excessive 
expansion of the inventory of combining forms and, in our opinion, makes the problem of distinguishing between various derivational strategies more complicated, thus requiring further studies into the subject.

\section{References:}

1. Arnold, I.V. The English Word. Moscow, 1973.

2. Bauer, Laurie. English Word-Formation. Cambridge Univ. Press, 1983.

3. Bradley, H. The Making of English. N.Y., 1957.

4. Fisher, R. Lexical Changes in Present-Day English, Oxford, 1998.

5. Ginzburg, R.S. et al. A Course in Modern English Lexicology, Moscow, 1979.

6. Nurnberg, M., Rozenblaum, M. All About Words, 1968.

7. Verdaguer, I. Making Sense of Neologisms, Forum, July/October, 1996.

8. Marchand, H. The Categories and Types of Present-Day English Word-Formation, 2ed., München, 1969.

9. Заботкина В.И. Новая лексика современного английского языка. М., 1989.

10. Кубрякова Е.С. Что такое словообразование. Изд. Наука, М., 1965.

11. Мешков О.Д. Словосложение в современном английском языке. М., 1985.

12. The Oxford Dictionary of New Words, compiled by Sara Tulloch, Oxford Univ. Press. 1991.

13. The Oxford Dictionary of New Words. / Ed. by Elizabeth Knowles, Oxford Univ. Press, 1997.

14. The New English-Russian Dictionary, edited by Yu.D. Apresyan, Moscow, 1999.

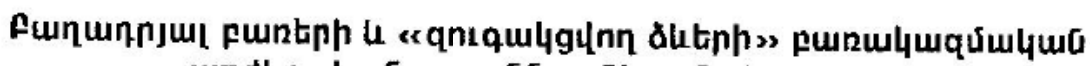

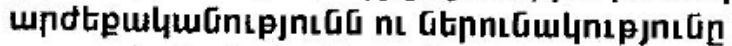

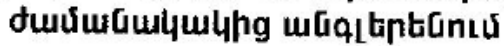

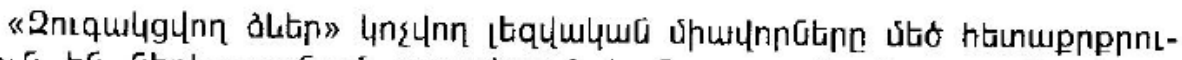

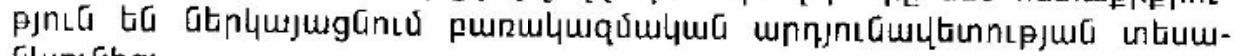
[ujneang:

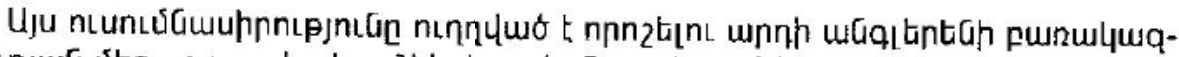

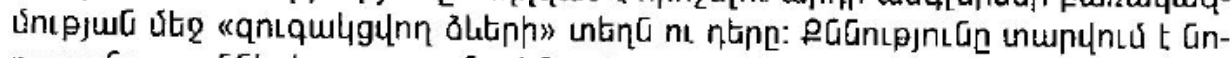

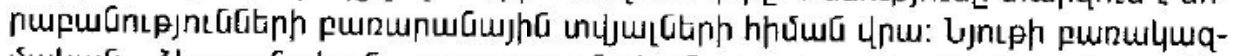

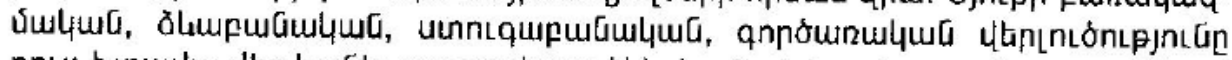

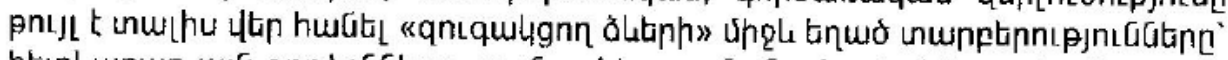

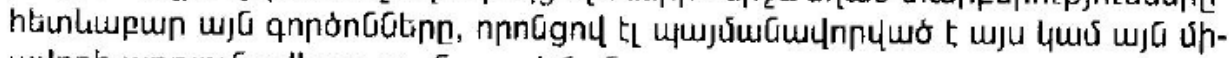

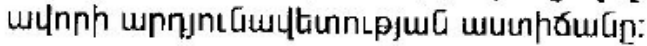

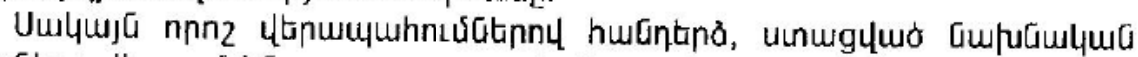

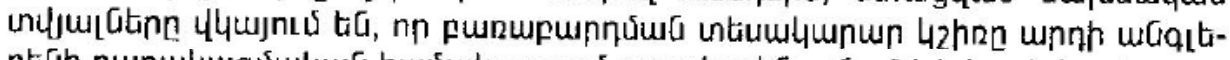

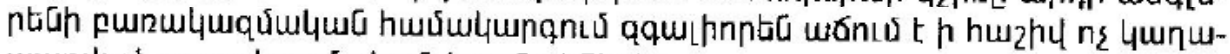

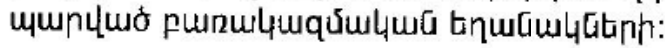

